Associations among measures of median, ulnar, and sural nerve conduction and age, skin temperature, sex, and anthropometric factors were evaluated in a population of 105 healthy, asymptomatic adults without occupational exposure to highly repetitive or forceful hand exertions. Height was negatively associated with sensory amplitude in all nerves tested $(P<$ 0.001 ), and positively associated with median and ulnar sensory distal latencies $(P<0.01)$ and sural latency $(P<0.001)$. Index finger circumference was negatively associated with median and ulnar sensory amplitudes $(P<0.05)$. Sex, in isolation from highly correlated anthropometric factors such as height, was not found to be a significant predictor of median or ulnar nerve conduction measures. Equations using age, height, and finger circumference for prediction of normal values are presented. Failure to adjust normal nerve conduction values for these factors decreases the diagnostic specificity and sensitivity of the described measures, and may result in misclassification of individuals. (c) 1992 John Wiley \& Sons, Inc.

Key words: nerve conduction studies $\bullet$ normal values $\bullet$ age $\bullet$ height $\bullet$ anthropometry

MUSCLE \& NERVE 15:1095-1104 1992

\title{
EFFECTS OF AGE, SEX, AND ANTHROPOMETRIC FACTORS ON NERVE CONDUCTION MEASURES
}

\author{
Diana s. STetson, PhD, James W. Albers, MD, PhD, BARBARA A. \\ SILVERSTEIN, PhD, and ROBERT A. WOLFE, PhD
}

Normal values for distal nerve conduction measures are needed for clinical evaluation of individual patients and as control data for epidemiologic studies of work-related peripheral nerve compression disorders such as carpal tunnel syndrome. Although many control populations have been described, $5,6,11,17,24,28,29,38$ variations in methodology, unspecified interelectrode distances, choice of digits, and type (or lack) of skin temperature control, as well as small sample sizes, limit their usefulness. Furthermore, while some reports specified that control subjects had no peripheral nerve dis-

From the Department of Environmental and Industrial Health, School of Public Health (Dr. Stetson), and Department of Neurology, Medical School (Dr. Albers). The University of Michigan, Ann Arbor, Michigan; Safety \& Health Assessment Research Program, Washington Department of Labor and Industries, Olympia, Washington (Dr. Silverstein); and Department of Biostatistics, School of Public Health. The University of Michigan, Ann Arbor, Michigan (Dr. Wolfe)

Acknowledgments: Partial funding was received from the General Motors Corporation. The authors thank Cathy Olsewski, REDT for performing the nerve conduction studies. The employees who participated are thanked for their time and good will.

Address reprint requests to Dr. J. W. Albers, Department of Neurology 1C $325 \mathrm{UH}$, Box 0032, The University of Michigan Medical Center, 1500 E. Medical Center Drive, Ann Arbor, MI 48109.

Accepted for publication March 2, 1992

CCC 0148-639X/92/101095-10

(C) 1992 John Wiley \& Sons, Inc ease, ${ }^{17,28,29}$ none fully described the occupations of their subjects or specified a population with low exposure to known occupational risk factors for carpal tunnel syndrome such as force, repetitiveness, and vibration. $8,34,39$

This study describes the distribution of median, ulnar, and sural nerve conduction measures in a population of healthy, working adults without exposure to forceful or repetitive hand exertions, or segmental vibration. The hypotheses of no association between each nerve conduction measure and independent variables known or hypothesized to affect nerve conduction were tested. These factors included age, ${ }^{4,19,26,38}$ skin temperature, ${ }^{10,22,31}$ height, ${ }^{7,21,32,35}$ and finger circumference. ${ }^{3}$ A square-shaped wrist has been negatively associated with distal median nerve conduction. ${ }^{18}$ Factors for which associations with specific nerve conduction measures were found to be statistically significant, biologically plausible, and clinically important were used to develop formulas which predict normal values.

\section{MATERIALS AND METHODS}

Population. Participants were salaried employees in a large corporation. Prior to age- and sex-strat- 
ified random selection, employees on jobs thought to have repetitive or forceful hand exertions were excluded (e.g., secretaries, word processors). Of 271 randomly selected employees, ${ }^{37} 249$ were available for participation (Table 1). Of these, 75 refused to participate and 69 were excluded, leaving 105 study participants. Exclusion criteria were neurological symptoms, a self-reported history of a systemic illness or disorder affecting the central or peripheral nervous systems, or occupational exposure to forceful or repetitive hand exertions. Participants returned a self-administered questionnaire which included information on age, height, medical history, occupational history, and symptoms in the hand/wrist during the preceding year.

Physical Evaluation. All subjects had a screening neurologic examination performed by a neurologist (J. A.) and an additional examination of the hand and wrist performed by a nurse (B. S.). Index finger circumference was measured at the middle of the proximal phalanx with a narrow cloth measuring tape. The wrist anterior-posterior and medial-lateral diameters were measured with engineering calipers at the distal wrist crease. ${ }^{18}$ Wrist ratio was calculated as the anterior-posterior diameter divided by the mediallateral diameter.

Table 1. Subject selection criteria.

\begin{tabular}{l}
\hline Consent form and questionnaire \\
sent to randomly selected employees \\
Less: \\
- Unavailable for participation $(n=22)$ \\
- Refused to participate $(n=75)$ \\
Excluded $(n=69)$ : \\
- Medical exclusion* $(n=28)$ \\
- $>21$ oz. ethanol/week or \\
self-described problem $(n=2)$ \\
- Numbness or paresthesia in hand \\
Occurring $>3$ times or lasting $>1$ week or \\
Occurring within prior week $(n=18)$ \\
- Pain in volar hand/wrist $(n=2)$ \\
- Current job has $\geq 4$ h/d with \\
repetitive/forceful hand exertions $(n=14)$ \\
- Prior job, within previous 2.5 years, with \\
repetitive/forceful hand exertions $(n=5)$ \\
Study population
\end{tabular}

*Medical reasons for exc/usion were: diabetes mellitus, rheumatoid arthritis, abnormal thyroid function within previous 10 years, carpal tunnel syndrome, cervical disk disease (or symptoms of paresthesias in hands radiating from the neck), pregnancy, renal disease, hemophilia, prior radial mononeuropathy, prior cerebral infarction, chemotherapy, or use of anticonvulsant medication.
Merve Conduction Studies. Nerve conduction studies were performed on the dominant hand of all subjects by the same certified electromyography technician. Using a TECA TD-5 electromyography machine and standard TECA surface electrodes, standard techniques of supramaximal percutaneous nerve stimulation and surface recording were employed. ${ }^{9}$ Anatomic landmarks and standardized stimulation to recording electrode distances are shown in Table 2. Skin temperatures were monitored at the proximal crease of digits II and $\mathrm{V}$ and at the midcalf. Temperature was maintained above $32^{\circ} \mathrm{C}$ in the hand, and above $30^{\circ} \mathrm{C}$ in the calf, with an electric heating pad.

Sensory nerve action potential and compound muscle action potential amplitudes were measured from the baseline to the negative peak. Sensory latencies were measured to the onset of the negative deflection and the negative peak. Motor latencies were measured to the onset of the initial negative deflection. Median motor conduction velocity for the forearm was calculated using proximal and distal onset latencies. Terminal sensory conduction velocities were calculated by dividing the distal distance by the onset latency. F-wave latencies were measured as the minimal latency in a series of five responses.

Statistics. Student's $t$ test was used to compare the difference between means for quantitative variables. Least squares regression was used for model building and hypothesis testing. The Pearson product moment was calculated for correlations of continuous variables. A $P$-value of $<0.05$ was used to define statistical significance. For model building, criteria for including an additional independent variable were that its coefficient have a $P$-value $<0.05$ and the partial $R^{2}$ associated with adding the variable be $>0.05$. Data for many of the nerve conduction measures did not follow a normal distribution. Prior to hypothesis testing, several transformations (natural log, square root, and inverse) were evaluated. Transformations resulting in a more normal distribution (Kolmogorov $D$-statistic and visual inspection of histograms/box plots) were used in the regression models. A model building approach was used for hypothesis testing. The independent variables were added in an order based on the strength of previously reported evidence for biologically plausible and significant associations: age, skin temperature, height, dominant index finger circumference, dominant wrist ratio, and sex. 
Table 2. Description of nerve conduction measurements ( $n=105$ ): mean \pm standard deviation (range).

\begin{tabular}{|c|c|c|c|c|c|}
\hline Nerve & Stimulate & $\begin{array}{c}\text { Recording electrodes } \\
\text { (interelectrode } \\
\text { distance) }\end{array}$ & Amplitude $(\mu \vee$ or $m V)$ & Latency (ms) & $\begin{array}{l}\text { Conduction velocity } \\
\qquad(\mathrm{m} / \mathrm{s})\end{array}$ \\
\hline \multirow[t]{3}{*}{ Median sensory } & Wrist & $\begin{array}{l}\text { Digit } 11, \text { proximal and } \\
\text { distal phalanxes; } \\
30-40 \mathrm{~mm} \text { apart } \\
(140 \mathrm{~mm})\end{array}$ & $\begin{array}{c}32.7 \pm 11.4 \\
(14-68)\end{array}$ & $\begin{array}{l}3.0 \pm 0.2 \\
(2.6-3.8)\end{array}$ & $\begin{array}{l}60.2 \pm 4.9 \\
(47-70)\end{array}$ \\
\hline & Wrist & $\begin{array}{l}\text { Digit } N \text {, proximal and } \\
\text { distal phalanxes; } \\
30-40 \mathrm{~mm} \text { apart } \\
(140 \mathrm{~mm})\end{array}$ & $\begin{array}{c}17.7 \pm 8.6 \\
(5-50)\end{array}$ & $\begin{array}{l}3.0 \pm 0.3 \\
(2.5-4.1)\end{array}$ & \\
\hline & $\begin{array}{l}\text { Midpaim, midthenar } \\
\text { crease }\end{array}$ & $\begin{array}{l}\text { Wrist, between PL* } \\
\text { and FCR tendons } \\
(80 \mathrm{~mm})\end{array}$ & $\begin{array}{l}115 \pm 41.5 \\
(40-225)\end{array}$ & $\begin{array}{l}1.8 \pm 0.2 \\
(1.4-2.4)\end{array}$ & \\
\hline \multirow[t]{2}{*}{ Median motor } & Wrist & $\begin{array}{l}\text { Thenar muscle } \\
(70 \mathrm{~mm})\end{array}$ & $\begin{array}{c}12.5 \pm 3.1 \\
\quad(4-19)\end{array}$ & $\begin{array}{l}3.2 \pm 0.4 \\
(2.4-4.2)\end{array}$ & \\
\hline & $\begin{array}{l}\text { Antecubital fossa, over } \\
\text { brachial pulse }\end{array}$ & $\begin{array}{l}\text { Thenar muscle } \\
\text { (measured) }\end{array}$ & & & $\begin{array}{l}56.7 \pm 2.9 \\
(50-64)\end{array}$ \\
\hline Median $F$ response & $\begin{array}{l}\text { Wrist; cathode } \\
\text { proximal }\end{array}$ & Thenar muscle & & $\begin{array}{l}27.1 \pm 2.2 \\
(21.6-32.6)\end{array}$ & \\
\hline \multirow[t]{3}{*}{ Ulnar sensory } & Wrist & $\begin{array}{l}\text { Digit } V \text {, proximal and } \\
\text { distal phalanxes; } \\
30-40 \mathrm{~mm} \text { apart } \\
(140 \mathrm{~mm})\end{array}$ & $\begin{array}{c}28.9 \pm 11.6 \\
(9-60)\end{array}$ & $\begin{array}{l}2.8 \pm 0.2 \\
(2.5-3.7)\end{array}$ & $\begin{array}{c}63.0 \pm 4.1 \\
(48-74)\end{array}$ \\
\hline & Wrist & $\begin{array}{l}\text { Digit IV, proximal distal } \\
\text { phalanxes; } 30-40 \\
\text { mm apart }(140 \mathrm{~mm})\end{array}$ & $\begin{array}{c}19.0 \pm 7.3 \\
(6-38)\end{array}$ & $\begin{array}{l}2.9 \pm 0.2 \\
(2.4-3.9)\end{array}$ & \\
\hline & Medial midpalm & Medial wrist $(80 \mathrm{~mm})$ & $\begin{array}{l}20.8 \pm 8.4 \\
\quad(8-52)\end{array}$ & $\begin{array}{l}1.7 \pm 0.1 \\
(1.5-2.2)\end{array}$ & \\
\hline Sural sensory & Midcalf & $\begin{array}{l}\text { Lateral malleolus } \\
\qquad(140 \mathrm{~mm})\end{array}$ & $\begin{array}{c}17.5 \pm 7.7 \\
(6-48)\end{array}$ & $\begin{array}{l}3.4 \pm 0.3 \\
(2.9-4.9)\end{array}$ & $\begin{array}{l}52.2 \pm 5.3 \\
(36-64)\end{array}$ \\
\hline
\end{tabular}

${ }^{*} P L=$ paimaris longus; $F C R=$ flexor carpi radialis

\section{RESULTS}

Population Description. The mean $( \pm \mathrm{SD})$ age for men was $42.7( \pm 12.6)$ years and for women it was $37.8( \pm 10.0)$ years $(P<0.05)$; age and sex distributions are reported elsewhere. ${ }^{37}$ Distributions of height, dominant hand index finger circumference, and dominant hand wrist ratio, stratified by sex, are summarized in Table 3. As a group, women were shorter and had a smaller finger cir-

Table 3. Population distribution of height, dominant hand index finger circumference, and wrist ratio, by sex.

\begin{tabular}{lccc}
\hline Measure & Fernale $(n=43)$ & Male $(n=62)$ & P-value \\
\hline Height $(\mathrm{cm})$ & $163.8 \pm 7.1$ & $180.1 \pm 6.4$ & 0.0001 \\
& $(150-180)$ & $(168-193)$ & \\
Dominant index finger & $6.2 \pm 0.4$ & $7.2 \pm 0.4$ & 0.0001 \\
Circumference $(\mathrm{cm})$ & $(5.2-7.0)$ & $(6.4-8.1)$ & \\
Dominant wrist ratio & $0.68 \pm 0.03$ & $0.68 \pm 0.03$ & NS \\
& $(0.62-0.76)$ & $(0.61-0.78)$ & \\
\hline
\end{tabular}

Values expressed in mean \pm SO (range). cumference than men, but there was considerable overlap between the two sexes. Skin temperature at the index finger had a range of 32.0 to $35.5^{\circ} \mathrm{C}$ with a mean of $34.0 \pm 0.82$. For the fifth digit, the range was 32.5 to $36.0^{\circ} \mathrm{C}(34.1 \pm 0.76)$, and at midcalf the range was 30.0 to $37.0^{\circ} \mathrm{C}(33.6 \pm 1.3)$.

Nerve Conduction Measures. Nerve conduction measurement distributions are shown in Table 2 with results for the median to ulnar comparison measures in Table 4. A description of the model building process is reported elsewhere ${ }^{37}$; results are shown in Tables 5 and 6 . Age was significantly associated with all sensory amplitude measures $(P$ $<0.001)$ and all conduction velocity and latency measures $(P<0.05$ ) except sural conduction velocity. There was no consistent pattern of association between digit temperature and median or ulnar nerve conduction, likely because of the narrow range of temperatures maintained as part of the study protocol. There was a strong association between temperature and sural conduction 
Table 4. Description of median to ulnar comparison measurements $(n=105)$.

\begin{tabular}{lcccc}
\hline & & \multicolumn{2}{c}{ Percentile } \\
\cline { 3 - 4 } Measurement & Mean \pm SD & 95th & 99 th & 0.8 \\
Median minus ulnar distal sensory latency (digit II vs. V) & $0.1 \pm 0.20$ & 0.4 & $-0.3-0.8$ \\
Median minus ulnar distal sensory latency (digit IV) & $0.1 \pm 0.25$ & 0.5 & 0.9 & $-0.4-1.2$ \\
Median minus ulnar sensory latency: midpalm (wrist) & $0.1 \pm 0.17$ & 0.4 & 0.6 & $-0.2-0.6$ \\
Median to ulnar amplitude ratio (digit II/digit V) & $1.2 \pm 0.34$ & 1.8 & 2.0 \\
\hline
\end{tabular}

velocity $(P<0.001)$, probably related to the wider range of temperatures at the midcalf.

Height was negatively associated with sensory amplitude in all nerves tested $(P<0.05)$, and positively associated with median and ulnar sensory distal latencies $(P<0.01)$ and sural latency $(P<$ $0.001)$. With age and skin temperature in the regression model, height explained an additional $25 \%$ of the variability in wrist-digit II median sensory amplitude. Index finger circumference was negatively associated with median and ulnar sensory amplitudes $(P<0.05)$. Adding finger circumference to regression models containing age, skin temperature, and height explained an additional $10 \%$ of the amplitude data variability. The association between median motor latency and wrist ratio $(P<0.001)$ explained an additional $12 \%$ of the variation.

Sex was highly correlated with height (Pearson correlation coefficient $=-0.77, P=0.0001$ ) and dominant index finger circumference (Pearson correlation coefficient $=-0.74, P=0.0001)$. For the upper extremity distal conduction measures, sex was not important when these anthropometric characteristics were included in the models. For the sural nerve, there was a significant association between both amplitude (smaller in females, $P<$ 0.05 ) and latency (longer in females, $P<0.01$ ).

To assess the relative importance of each independent variable included in the regression models, the standardized regression coefficient (SRC) is listed below each coefficient (Tables 5 and 6), where:

$$
\mathrm{SRC}=\begin{aligned}
& \text { regression } \\
& \text { coefficient }
\end{aligned} *\left(\frac{\mathrm{SD} \text { of independent variable }}{\mathrm{SD} \text { of dependent variable }}\right)
$$

The SRC represents the change in the dependent nerve conduction measure (in units of its standard deviation) per unit change in the independent variable (in units of its standard deviation), and thus, is dimensionless. Although the magnitude of an SRC may not always reflect the importance of the independent variable, it is reasonable to use this measure to look for patterns of relative importance.

Overall, for upper extremity sensory amplitudes, age and index finger circumference appeared to be the most important independent variables. As an example of the range of amplitudes associated with a change in finger circumference, the prediction equation (Table 5) was used to calculate predicted values for wrist-digit II amplitude, using constant mean values for age and height. For a finger circumference of $8.0 \mathrm{~cm}$ (mean $+2 \mathrm{SD}$ ) the predicted amplitude is 25.0 $\mu \mathrm{V}$, while for a circumference of $5.5 \mathrm{~cm}$ (mean $2 \mathrm{SD}$ ) predicted amplitude is $39.5 \mu \mathrm{V}$. These results demonstrate the magnitude of effect that finger circumference can have on sensory amplitude.

For median and ulnar distal sensory conduction velocities and latencies, age and height appeared to be the most important variables. Because the conduction velocity data were never transformed, the magnitude of change in nerve conduction caused by a change in age or height can be assessed by looking at the regression functions for these measures (Tables 5 and 6). For the upper extremity conduction velocities shown, there was about a $1 \mathrm{~m} / \mathrm{s}$ decrease in conduction velocity per decade increase in age. For the wristdigit measures, there was about a $0.2 \mathrm{~m} / \mathrm{s}$ decrease in conduction velocity for each centimeter increase in height $(0.5 \mathrm{~m} / \mathrm{s}$ per inch). Over a narrow range of age and/or height the magnitude of change was relatively minor, but large differences could have a substantial impact on the normal range of these measures. For median sensory conduction velocity and latencies, wrist ratio appeared to be the least important variable. A $\pm 2 \mathrm{SD}$ change in age produced a much greater change in the predicted value for wrist-digit IV latency ( 2.8 to $3.3 \mathrm{~ms}$ ) than did a $\pm 2 \mathrm{SD}$ variation in wrist ratio (2.9 to $3.1 \mathrm{~ms}){ }^{37}$ 
Table 5. Summary of model building and prediction equations: upper extremity (prediction equations which are different from summary models are shown in italics).

\begin{tabular}{|c|c|c|c|c|c|c|c|}
\hline \multirow[b]{2}{*}{$\begin{array}{l}\text { Dependent } \\
\text { variable }\end{array}$} & \multirow[b]{2}{*}{ Constant } & \multicolumn{3}{|c|}{$\begin{array}{c}\text { Regression coefficients } \\
\text { (standardized regression coefficients) }\end{array}$} & \multirow[b]{2}{*}{$\begin{array}{l}\text { Wrist } \\
\text { ratio* }\end{array}$} & \multirow[b]{2}{*}{ Model $R^{2}$} & \multirow[b]{2}{*}{$\stackrel{2 \times}{(\mathrm{MSE})^{1 / 2}}$} \\
\hline & & $\begin{array}{l}\text { Age } \\
(y r)\end{array}$ & $\begin{array}{l}\text { Height } \\
(\mathrm{cm})\end{array}$ & $\begin{array}{l}\text { Index finger } \\
\text { circumference } \\
\text { (cm) }\end{array}$ & & & \\
\hline \multicolumn{8}{|l|}{ Median sensory } \\
\hline \multicolumn{8}{|l|}{ Wrist-digit $\|$} \\
\hline Square root of amplitude & 14.0 & $\begin{array}{l}-0.035 \S \\
(0.42)\end{array}$ & $\begin{array}{l}-0.020 \dagger \\
(0.21)\end{array}$ & $\begin{array}{c}-0.51 \ddagger \\
(0.32)\end{array}$ & & 0.51 & 1.392 \\
\hline Conduction velocity & 107.6 & $\begin{array}{l}-0.13 \S \\
(0.32)\end{array}$ & $\begin{array}{r}-0.14 \S \\
(0.30)\end{array}$ & & $\begin{array}{l}-25.4 \\
(0.18)\end{array}$ & 0.22 & - \\
\hline Conduction velocity & 89.5 & $-0.12 \ddagger$ & $-0.14 t$ & & & 0.17 & 8.858 \\
\hline Negative inverse of latency & -0.58 & $\begin{array}{l}0.00083 \S \\
(0.38)\end{array}$ & $\begin{array}{l}0.00068 \neq \\
(0.27)\end{array}$ & & $\begin{array}{l}0.14 \dagger \\
(0.18)\end{array}$ & 0.24 & - \\
\hline $\begin{array}{l}\text { Negative inverse of latency } \\
\text { Wrist-Digit IV }\end{array}$ & -0.48 & $0.00078 \S$ & $0.00066 \neq$ & & & 0.21 & 0.046 \\
\hline Natural log of amplitude & 6.8 & $\begin{array}{l}-0.017 \S \\
(0.42)\end{array}$ & $\begin{array}{l}-0.0089 \dagger \\
(0.19)\end{array}$ & $\begin{array}{c}-0.27 \S \\
(0.37)\end{array}$ & & 0.54 & 0.642 \\
\hline Negative inverse of latency & -0.67 & $\begin{array}{l}0.0012 \S \\
(0.44)\end{array}$ & $\begin{array}{l}0.00079 \ddagger \\
(0.26)\end{array}$ & & $\begin{array}{r}0.22 \ddagger \\
(0.23)\end{array}$ & 0.29 & - \\
\hline $\begin{array}{l}\text { Negative inverse of latency } \\
\text { Midpalm-wrist }\end{array}$ & -0.51 & $0.0011 \S$ & $0.00076 \neq$ & & & 0.24 & 0.056 \\
\hline Natural log of amplitude & 5.24 & $\begin{array}{l}-0.014 \S \\
(0.43)\end{array}$ & & & & 0.19 & 0.684 \\
\hline Negative inverse of latency & -0.88 & $\begin{array}{l}0.0018 \S \\
(0.36)\end{array}$ & & & $\begin{array}{r}0.35 \dagger \\
(0.20)\end{array}$ & 0.15 & - \\
\hline $\begin{array}{l}\text { Negative inverse of latency } \\
\text { Median motor }\end{array}$ & -0.64 & $0.0016 \S$ & & & & 0.11 & 0.110 \\
\hline Amplitude: no statistically signi & ficant asso & on with the tes & independent & variables & & & \\
\hline Conduction velocity & 60.0 & $\begin{array}{l}-0.081 \S \\
(0.33)\end{array}$ & & & & 0.11 & 5.572 \\
\hline Negative inverse of latency & -0.85 & $\begin{array}{l}0.00057 \dagger \\
(0.19)\end{array}$ & $\begin{array}{l}0.0017 \S \\
(0.48)\end{array}$ & & $\begin{array}{c}0.32 \S \\
(0.30)\end{array}$ & 0.34 & - \\
\hline Negative inverse of latency & -0.61 & 0.00044 & $0.0016 \S$ & & & 0.25 & 0.064 \\
\hline \multicolumn{8}{|l|}{ Median F response } \\
\hline Latency & -3.33 & $\begin{array}{c}0.04 \S \\
(0.22)\end{array}$ & $\begin{array}{c}0.17 \S \\
(0.77)\end{array}$ & & & 0.66 & 2.644 \\
\hline \multicolumn{8}{|l|}{ Ulnar sensory } \\
\hline \multicolumn{8}{|l|}{ Wrist-digit $V$} \\
\hline Natural log of amplitude & 6.5 & $\begin{array}{l}-0.015 \S \\
(0.42)\end{array}$ & $\begin{array}{l}-0.0054 \\
(0.14)\end{array}$ & $\begin{array}{c}-0.25 \S \\
(0.38)\end{array}$ & & 0.51 & 0.582 \\
\hline Conduction velocity & 98.1 & $\begin{array}{l}-0.099 \S \\
(0.29)\end{array}$ & $\begin{array}{l}-0.18 \S \\
(0.46)\end{array}$ & & & 0.31 & 6.876 \\
\hline Negative inverse of latency & -0.53 & $\begin{array}{l}0.00071 \S \\
(0.37)\end{array}$ & $\begin{array}{l}0.00083 \S \\
(0.38)\end{array}$ & & & 0.29 & 0.038 \\
\hline \multicolumn{8}{|l|}{ Wrist-Digit IV } \\
\hline Natural log of amplitude & 5.96 & $\begin{array}{l}-0.015 \S \\
(0.45)\end{array}$ & $\begin{array}{c}-0.0088 \dagger \\
(0.24)\end{array}$ & $\begin{array}{c}-0.14 \dagger \\
(0.22)\end{array}$ & & 0.45 & 0.588 \\
\hline Negative inverse of latency & -0.55 & $\begin{array}{l}0.00080 \S \\
(0.36)\end{array}$ & $\begin{array}{l}0.00097 \S \\
(0.38)\end{array}$ & & & 0.29 & 0.046 \\
\hline \multicolumn{8}{|l|}{ Midpalm-wrist } \\
\hline Square root of amplitude & 10.5 & $\begin{array}{c}-0.034 \S \\
(0.45)\end{array}$ & $\begin{array}{c}-0.026 \S \\
(0.31)\end{array}$ & & & 0.31 & 1.510 \\
\hline Negative inverse of latency & -0.78 & $\begin{array}{l}0.00071 \dagger \\
(0.22)\end{array}$ & $\begin{array}{l}0.00090 \ddagger \\
(0.25)\end{array}$ & & & 0.12 & 0.070 \\
\hline
\end{tabular}

${ }^{\star}$ Wrist ratio $=$ anterior-posterior diameter/medial-lateral diameter.

$\dagger P<0.05 ; \ddagger P<0.01 ; \S P<0.001$ 
Table 6. Prediction equations: lower extremity

\begin{tabular}{|c|c|c|c|c|c|c|c|}
\hline \multirow[b]{2}{*}{$\begin{array}{l}\text { Dependent } \\
\text { variable }\end{array}$} & \multirow[b]{2}{*}{ Constant } & \multicolumn{3}{|c|}{$\begin{array}{c}\text { Regression coefficients } \\
\text { (standardized regression coefficients) }\end{array}$} & \multirow[b]{2}{*}{$\operatorname{Sex}^{\star}$} & \multirow[b]{2}{*}{ Model $R^{2}$} & \multirow[b]{2}{*}{$\begin{array}{c}2 \times \\
(M S E)^{1 / 2}\end{array}$} \\
\hline & & $\begin{array}{l}\text { Age } \\
(y r)\end{array}$ & $\begin{array}{l}\text { Height } \\
(\mathrm{cm})\end{array}$ & $\begin{array}{c}\text { Midcalf } \\
\text { temperature } \\
\left({ }^{\circ} \mathrm{C}\right)\end{array}$ & & & \\
\hline \multicolumn{8}{|l|}{ Sural sensory } \\
\hline Natural log of amplitude & 7.6 & $\begin{array}{l}-0.019 \S \\
(0.52)\end{array}$ & $\begin{array}{l}-0.023 \S \\
(0.55)\end{array}$ & & $\begin{array}{r}-0.29 \dagger \\
(0.33)\end{array}$ & 0.37 & 0.694 \\
\hline Conduction velocity & 30.7 & $\begin{array}{r}-0.051 \\
(0.12)\end{array}$ & $\begin{array}{c}-0.27 \S \\
(0.53)\end{array}$ & $\begin{array}{l}2.1 \S \\
(0.52)\end{array}$ & $\begin{array}{l}-2.6 \\
(0.24)\end{array}$ & 0.47 & 7.986 \\
\hline Negative inverse of latency & -0.30 & $\begin{array}{l}0.00052 \ddagger \\
(0.23)\end{array}$ & $\begin{array}{l}0.0018 \S \\
(0.66)\end{array}$ & $\begin{array}{l}-0.0099 \S \\
(0.47)\end{array}$ & $\begin{array}{l}0.023 \ddagger \\
(0.41)\end{array}$ & 0.48 & 0.042 \\
\hline
\end{tabular}

*Sex coded as male $=0$; female $=1$.

$+P<0.05 ; \ddagger P<0.01 ; \S P<0.001$

\section{DIScussion}

The results describe the statistical significance of associations. Final model development also included a review of whether: (a) the association was biologically plausible; (b) the magnitude of association was large enough to be of clinical importance; (c) the association was supported by previous studies; and (d) the associated independent variable was intrinsic or could be controlled through standardized testing procedures.

Age. The decrease in nerve conduction velocity and sensory amplitude associated with increasing age has been well documented, ${ }^{4,6,19,25-27,38}$ and attributed to a decreased number of nerve fibers, ${ }^{25}$ a reduction in fiber diameter, ${ }^{19,25}$ and changes in the fiber membrane. ${ }^{4,23}$ The $1.3 \mathrm{~m} / \mathrm{s}$ decrease in median sensory distal conduction velocity and the $0.8 \mathrm{~m} / \mathrm{s}$ decrease in motor conduction velocity per decade of aging found in this study are comparable to previous reports. ${ }^{6,38}$ Our data showed an average loss of about $5 \mu \mathrm{V}$ per decade for wrist-digit II sensory amplitude. This was somewhat larger than the $1.5 \mu \mathrm{V}$ per decade loss in digit III-wrist sensory amplitude reported by Buchthal et al. ${ }^{6}$ or the $3.8 \mu \mathrm{V}$ per decade loss in wrist-digit III sensory amplitude reported by Tackmann. ${ }^{38}$ Although the magnitude of change is relatively small within a narrow age range, it does affect predicted normal values. A prolonged latency in a young age group will be missed if normal values based on an older age group are used. ${ }^{6}$

Temperature. Over relatively wide temperature ranges (e.g., 21 to $36^{\circ} \mathrm{C}^{4}$ or 29 to $38^{\circ} \mathrm{C}^{15}$ ), motor and sensory nerve conduction velocities have a positive linear relationship with body temperature. $^{10,20}$ With cooling, motor and sensory amplitudes increase and conduction values decrease. $^{10,16,22,31}$ Cooling is thought to affect muscle and nerve membrane function, particularly the sodium ion channel. ${ }^{10,20,31}$

Our ability to detect true associations was limited by the relatively narrow temperature range in the upper extremity $\left(32\right.$ to $36^{\circ} \mathrm{C}$ ), as well as sources of error such as the difference between surface temperature and the near nerve temperature. ${ }^{10}$ For the sural nerve, where there was a $7^{\circ}$ temperature range $\left(30\right.$ to $\left.37^{\circ} \mathrm{C}\right)$, relatively strong associations between surface temperature and both conduction velocity and latency were found (partial $R^{2}$ from 0.29 to 0.35 ). The slope of 2.3 $\mathrm{m} / \mathrm{s}$ per ${ }^{\circ} \mathrm{C}$ corresponds to previous reports. ${ }^{4,36}$ Unlike individual characteristics such as age and height, temperature is an extrinsic factor which can be controlled. We recommend use of a standard protocol for warming the extremities, as proposed by others. ${ }^{10,20}$

Height. The negative relationship between height and sensory amplitudes was a consistent finding in all three sensory nerves tested. While controlling for age and surface temperature, height explained much of the sensory amplitude variation (partial $R^{2}$ in 0.20 to 0.25 range). Our results duplicated those of others who have found a strong negative correlation between height and either sural or peroneal conduction velocity. ${ }^{7,21,33,35}$ Controlling for age and temperature, the $0.17 \mathrm{~m} / \mathrm{s}$ decrease in sural conduction velocity per centimeter increase in height $(0.44 \mathrm{~m} / \mathrm{s}$ per inch) was somewhat larger than previously reported. ${ }^{32,35}$ Also, controlling for 
sex, there was a $0.27 \mathrm{~m} / \mathrm{s}$ per centimeter decrease $(0.68 \mathrm{~m} / \mathrm{s}$ per inch) (Table 6). We also found strong associations between height and both median and ulnar sensory terminal conduction velocities and latencies (average sensory terminal conduction velocity decrease of $0.16 \mathrm{~m} / \mathrm{s}$ per centimeter). This was consistent with Lang's ${ }^{21}$ report of a positive correlation between height and radial sensory conduction velocity. While differing from the lack of correlation between height and median sensory conduction velocity reported by Soudmand, ${ }^{35}$ our larger population, and its wider age range, may have given more power to detect a true association. In addition, the associations were found only for distal measures (e.g., wrist-digit or midpalm-wrist), whereas Soudmand reported forearm conduction velocity.

A negative correlation between distal fiber diameter and height may best explain both decreased conduction velocity and amplitude. Campbell $^{7}$ proposed that a decrease in diameter occurs abruptly at a given distance from the cell body. In mature rabbit nerves, Williams ${ }^{40}$ found that peripheral motor axon diameter was about half that of ventral spinal nerve root fibers and, despite an increase in myelin sheath thickness, there was an overall decrease in total fiber diameter. Buchthal and Rosenfalck ${ }^{4}$ reported histologic characteristics of median nerve fibers from 2 men and found no evidence of nerve fiber tapering between the wrist and axilla, but the digital nerve mode diameter was about $3 \mu \mathrm{m}$ smaller than that found proximally. Our results, which showed an association with median sensory distal conduction velocities, are consistent with the contention that tapering occurs distal to the wrist. The association between height and ulnar, but not median, midpalm-wrist sensory measures may have an anatomical basis, e.g., more proximal tapering in the ulnar than median nerve, or may be an artifact.

There is strong evidence for including height in models used to predict normal values for distal lower extremity measures ${ }^{7,21,32,35}$ and F-wave latencies. ${ }^{33}$ There is increasing evidence that height is an important predictor of distal sensory upper extremity nerve conduction. ${ }^{21,32}$ Use of "normal" values based on a control population is inappropriate, because they will be influenced by the population's height distribution. ${ }^{33}$

Finger Circumference. Bolton ${ }^{3}$ has reported a negative correlation between finger circumference and both median and ulnar antidromic sensory amplitudes. Although we inferred digit $\mathrm{V}$ circum- ference from that measured for digit II, our results replicated his findings. With age and height held constant, finger circumference had a substantial effect on distal sensory amplitude. Differences in finger circumference are due primarily to differences in bone mass and subcutaneous tissue. Bone mass is presumed to be positively correlated with height, which was controlled for in our analysis. Therefore, the association between finger circumference and amplitude is probably related to subcutaneous tissue depth, which is the major determinant of the distance between the digital nerves and the recording (ring) electrode. Since amplitude decreases as the distance between nerve and electrode increases, ${ }^{4}$ our results were in the expected direction.

Wrist Ratio. A positive association between wrist ratio and median sensory latency has been reported in a mixed population of patients and control subjects ${ }^{18}$ and, for median motor latency, in a population with symptoms compatible with carpal tunnel syndrome. ${ }^{13}$ We found weak positive associations between wrist ratio and both median sensory and motor latencies which were absent when wrist ratio was tested in single factor models. No biological hypothesis for the relationship between wrist ratio and median nerve latency has been proposed, and the observed association seems counterintuitive. In the biomechanical model of the wrist proposed by Armstrong, ${ }^{1}$ a small radius of tendon curvature is predicted to increase the risk of tendon and synovial trauma within the carpal tunnel area; subsequent synovitis and synovial membrane thickening cause median nerve compression. ${ }^{2}$ In contrast, a large wrist ratio (more "box-shaped" wrist) would be associated with a large radius of tendon curvature. In addition, Richman $^{30}$ has pointed out that measurements based on bony landmarks cannot be used to estimate the distal third of the carpal tunnel, a potential area of nerve compression, and Winn ${ }^{41}$ has shown that carpal tunnel area itself is not a risk factor for carpal tunnel syndrome. Because of the relatively weak associations and small magnitudes of effect in this study, and the lack of a biologically plausible model, we do not recommend controlling for wrist ratio. However, the association is intriguing and subsequent biological explanations may increase our understanding of functional anatomy within the carpal tunnel.

Sex. Like others who have reported that differences in conduction velocity or amplitude initially 
attributed to sex disappeared once anatomical factors were taken into account, ${ }^{3,7,35}$ we found no association between sex and median or ulnar nerve conduction measures that could not be attributed to the correlation between sex and height or sex and dominant finger circumference. For the sural nerve, using a model which also included age, midcalf temperature, and height, women were found to have a significantly smaller amplitude and slower conduction velocity then men. The most plausible hypothesis is that both sex and sural nerve conduction and amplitude are correlated with an anatomical or physiological factor which we did not measure. Although some have recommended that normal values be segregated by sex, as a surrogate measure for anatomical differences, ${ }^{3}$ we feel it is more appropriate to incorporate age, height, and finger circumference into regression models used to predict normal values because there is considerable overlap between the female and male distributions of these factors (Table 3).

\section{SUMMARY OF RECOMMENDATIONS}

Adjusting normal nerve conduction values for known anatomical or physiological determinants such as age, height, and finger circumference increases the diagnostic sensitivity of these measures. $^{3,21,35}$ In Table 7 , the predicted normal ranges for 2 subjects with different characteristics are shown and compared to the conventional abnormal value (mean $\pm 3 \mathrm{SD}$ ) used in our laboratory. The predicted values and confidence intervals were calculated from the regression models shown in Table 5 . The values of the independent variables used in each model (e.g., age $=25$ ) are shown for each subject. Using the laboratory criteria, a value within the $99 \%$ confidence interval of normal results for the tall, older individual could mistakenly be interpreted as abnormal (e.g., wrist-digit II sensory amplitude greater than 7.3 $\mu \mathrm{V}$ and less than $15 \mu \mathrm{V}$ ) and might be used to validate unnecessary surgery. Conversely, values beyond the $99 \%$ confidence interval (i.e., abnormal) for the relatively short 25-year-old could be interpreted as normal and result in a failure to diagnose and treat. This is a predictable occurrence whenever the normal range is based on values found for the control population as a whole.

Predicting normal values in the context of pertinent individual characteristics will increase sensitivity, and possibly specificity, of electrodiagnostic procedures. Although rarely used in the electrodiagnostic field, prediction formulae developed in the spirometric lung function field have consistently included height, sex, age, and ethnic group-factors known to affect lung function. ${ }^{12}$ While there is continuing debate about the best statistical method to use, ${ }^{12,14}$ computer technology makes the development of an algorithm which

Table 7. Comparison of predicted normal range derived from equations with laboratory definition of an abnormal value.

\begin{tabular}{|c|c|c|c|c|}
\hline Measure & $\begin{array}{l}\text { Individual } \\
\text { characteristics }\end{array}$ & $\begin{array}{l}\text { Predicted } \\
\text { value }\end{array}$ & $\begin{array}{c}99 \% \\
\text { confidence } \\
\text { interva| }\end{array}$ & $\begin{array}{l}\text { Abnormal } \\
\text { per lab. }\end{array}$ \\
\hline \multicolumn{5}{|c|}{ W-digll sensory amplitude } \\
\hline & $\begin{array}{l}\text { Age } 25,163 \mathrm{~cm}, 5.8-\mathrm{cm} \\
\text { index finger circumference }\end{array}$ & $47.6 \mu \mathrm{V}$ & $(25.7-76.1)$ & \multirow[b]{2}{*}{$<15 \mu V$} \\
\hline & $\begin{array}{l}\text { Age } 55,183 \mathrm{~cm}, 7.6-\mathrm{cm} \\
\text { index finger circumference }\end{array}$ & $20.4 \mu \mathrm{V}$ & $(7.27-40.2)$ & \\
\hline \multicolumn{5}{|c|}{ W-digll sensory latency } \\
\hline & Age $25,163 \mathrm{~cm}$ & $2.8 \mathrm{~ms}$ & $(2.4-3.4)$ & \multirow[b]{2}{*}{$>3.9 \mathrm{~ms}$} \\
\hline Midnalm & Age 55, $183 \mathrm{~cm}$ & $3.1 \mathrm{~ms}$ & $(2.6-3.9)$ & \\
\hline & Age 25 & $1.7 \mathrm{~ms}$ & $(1.4-2.2)$ & \multirow[b]{2}{*}{$>2.5 \mathrm{~ms}$} \\
\hline Median $n$ & $\begin{array}{l}\text { Age } 55 \\
\text { latency }\end{array}$ & $1.8 \mathrm{~ms}$ & $(1.4-2.5)$ & \\
\hline & Age $25,163 \mathrm{~cm}$ & $2.9 \mathrm{~ms}$ & $(2.4-3.9)$ & \multirow[b]{2}{*}{$>4.5 \mathrm{~ms}$} \\
\hline & Age $55,183 \mathrm{~cm}$ & $3.4 \mathrm{~ms}$ & $(2.7-4.7)$ & \\
\hline
\end{tabular}


predicts the normal range of values for each individual in the context of pertinent characteristics a relatively simple task.

Predicted normal values can be calculated from the regression equations given in Tables 5 and 6 , or the $95 \%$ prediction interval can be estimated from the following equation:

$$
95 \% \text { prediction interval }=Y \pm 2 *\left[(\mathrm{MSE})^{1 / 2}\right]
$$

where $Y=$ the predicted value, and $\mathrm{MSE}=$ the mean square for error. The values for $2 *\left[(\mathrm{MSE})^{1 / 2}\right]$ are given in Tables 5 and 6 . An abnormal value can be defined as one which is outside the $95 \%$ prediction interval.

None of the independent variables tested helped predict the outcome for median motor amplitude or the median-to-ulnar comparison measures. The latter measures utilized either the ratio or the difference between a median and an ulnar nerve measure in the same hand in the same person. It is therefore expected that comparison measures need not be corrected for age, height, or skin temperature. The standard deviations for median motor amplitude and the comparison measures are shown in Tables 2 and 4. Comparison measures data did not follow a normal distribution; percentile and range may give more appropriate descriptive information than increments of the standard deviation.

In summary, in randomly selected adults without occupational exposure to high force or repetitive hand exertions, age, height, and index finger circumference were found to be important predictors of median, ulnar, and sural nerve conduction measures. These factors were incorporated into equations used to predict normal values for these measures.

\section{REFERENCES}

1. Armstrong TJ, Chaffin DB: Some biomechanical aspects of the carpal tunnel. J Biomech 1979;12:567-570.

2. Armstrong TJ, Silverstein BA: Upper-extremity pain in the workplace-role of usage in causality, in Clinical Concepts in Regional Musculoskeletal Illiness. Grune \& Stratton, 1987.

3. Bolton CF, Carter KM: Human sensory nerve compound action potential amplitude: variation with sex and finger circumference. J Neurol Neurosurg Psychiatry 1980;43:925928.

4. Buchthal F, Rosenfalck A: Evoked action potentials and conduction velocity in human sensory nerves. Brain Res 1966;3:I-122.

5. Buchthal F, Rosenfalck A: Sensory conduction from digit to palm and from palm to wrist in the carpal tunnel syndrome. J Neurol Neurosurg Psychiatry 1971;34:243-252.
6. Buchthal F, Rosenfalck A, Trojaborg W: Electrophysiological findings in entrapment of the median nerve at wrist and elbow. I Neurol Neurosurg Psychialry 1974;37:340-360.

7. Campbell WW, Ward LC, Swift TR: Nerve conduction velocity varies inversely with height. Muscle Nerve 1981; $4: 520-523$

8. Cannon LJ, Bernacki EJ, Walter SD: Personal and occupational factors associated with carpal tunnel syndrome. $J \mathrm{OC}_{\mathrm{C}}$ cup Med 1981;23:255-258.

9. Daube JR: Nerve conduction studies, in Aminoff MJ (ed): Electrodiagnosis in Clinical Neurology. New York, Churchill Livingstone, 1980, pp 229-264.

10. Denys EH: The role of temperature in electromyography. AAEE Minimonograph \#14, 1980.

11. Eklund G: A new electrodiagnostic procedure for measuring sensory nerve conduction across the carpal tunnel. Upsala J Med Sci 1975;80:63-64.

12. Goldsmith JR, Scharf SM, Israeli R: Pulmonary function screening and monitoring in occupational health. $J$ Occup Med 1986;28:656-663.

13. Gordon C, Johnson EW, Gaten PF, Ashton JJ: Wrist ratio correlation with carpal tunnel syndrome in industry. $\mathrm{Am} \mathrm{J}$ Phys Med Rehabil 1988;67:270-272.

14. Hankinson JL: Pulmonary function testing in the screening of workers: guidelines for instrumentation, performance, and interpretation. J Occup Med 1986;28:10811092 .

15. Henriksen JD: Conduction velocity of motor nerves in normal subjects and in patients with neuromuscular disorders. Thesis, University of Minnesota, Minneapolis, as cited in refs. 10 and 20,1966

16. Hulley WC, Wilbourne AJ, McGinty K: Sensory nerve action potential amplitudes; alterations with temperature. Electrocephalogr Clin Neurophysiol 1978;45:24P.

17. Jackson DA, Clifford JC: Electrodiagnosis of mild carpal tunnel syndrome. Arch Phys Med Rehabil 1989;70:199-204.

18. Johnson EW, Gaten T, Poindexter D, Bowers D: Wrist dimensions: correlation with median sensory latencies. Arch Phys Med Rehabil 1983;64:556-557.

19. Kemble F: Conduction in the normal adult median nerve the different effect of ageing in men and women. Electromyography 1967; VII:275-288.

20. Kimura J: Electrodiagnesis in Diseases of Nerve and Muscle: Principles and Practice (2nd ed.). Philadelphia, F.A. Davis, 1989, chap. 5.

21. Lang AH, Forsstrom J, Bjorkqvist SE, Kuusela V: Statistical variation of nerve conduction velocity. I Neurol $S c i$ 1977;32:229-241.

22. Lang AH, Puusa A: Dual influence of temperature on compound nerve action potential. J Neurol Sci 1981;51:8188.

23. Lascelles RG, Thomas PK: Changes due to age in internodal length in the sural nerve in man. $J$ Newrol Neurasurg Psychiatry 1966;29:40-44.

24. Loong SC, Seah CS: Comparison of median and ulnar sensory nerve action potentials in the diagnosis of the carpal tunnel syndrome. J Neurol Neurosurg Psychiatry 1971; 34:750-754.

25. Mayer RF: Nerve conduction studies in man. Neurology 1963;13:1021-1030.

26. Melvin JL, Harris DH, Johnson EW: Sensory and motor conduction velocities in the ulnar and median nerves. Arch Phys Med Rehabil 1966;47:511-519.

27. Miglietta $O E$ : Sensory conduction of digital nerve fibers Am J Phys Med 1969;48:78-84.

28. Mills KR: Orthodromic sensory action potentials from palmar stimulation in the diagnosis of carpal tunnel syndrome. J Neurol Neurosurg Psychiatry 1985;48:250-255.

29. Monga TN, Shanks GL, Poole BJ: Sensory palmar stimulation in the diagnosis of carpal tunnel syndrome. Arch Phys Med Rehabil 1985;66:598-600.

30. Richman JA, Gelberman RH, Rydevik BL, et al: Car- 
pal tunnel volume determination by magnetic resonance imaging three-dimensional reconstruction. J Hand Surg 1987;12A:712-717.

31. Ricker K, Hertel G, Stodieck G: Increased voltage of the muscle action potential of normal subjects after local cooling. J Neurol 1977;216:33-38.

32. Rivner MH, Swift TR, Crout BO, Rhodes KP: Toward more rational nerve conduction interpretations: the effect of height. Muscle Nerve 1990;13:232-239.

33. Russo LS: Height influences $F$ response parameters in the upper extremity. Electromyogr Clin Neurophysiology 1985; 25:165- 173 .

34. Silverstein BA, Fine LJ, Armstrong TA: Occupational factors and carpal tunnel syndrome. Am $J$ Indust Med 1987;11:343-358.

35. Soudmand R, Ward LC, Swift TR: Effect of height on nerve conduction velocity. Neurology $(N Y)$ 1982;32:407410.

36. Stegeman DF, DeWeerd JP: Modelling compound action potentials of peripheral nerves in situ. II. A study of the influence of temperature. Electroencephalogr Clin Neurophysiol 1982;54:516-529.

37. Stetson DS: Median and ulnar nerve conduction measures in control and industrial populations: associations with ergonomic risk factors. Doctoral dissertation. The University of Michigan, 1991, chap. 2.

38. Tackmann W, Keaser He, Magun HG: Comparison of orthodromic and antidromic sensory nerve conduction velocity measurements in the carpal tunnel syndrome. $J \mathrm{Neu}$ rol 1981;224:257-266.

39. Wieslander G, Norback D, Ljuhlin CJC: Carpal tunnel syndrome (CTS) and exposure to vibration, repetitive wrist movements, and heavy manual work: a case-refinement study. Brit J Indus Med 1989;46:43-47.

40. Williams PL, Wendell-Smith CP: Some additional parametric variations between peripheral nerve fibre populations. $J$ Anat 1976;109:505-526.

41. Winn FJ, Habes DJ: Carpal tunnel area as a risk factor for carpal tunnel syndrome. Muscle Nerve 1990;13:254-258. 